\title{
HOTEL QUITANDINHA: PERMANÊNCIAS E RUPTURAS NA EXPERIÊNCIA MULTISSENSORIAL
}

\author{
TALIN, Layla Christine Alves \\ UCP, e-mail: laylatalin@yahoo.com.br \\ TRINDADE, Ana Beatriz Constâncio \\ UCP, e-mail: anabeatrizctrindade@hotmail.com \\ GUETTNAUER, Danielle \\ UCP, e-mail: daniguettnaver@gmail.com \\ BALDEZ, Julia da Silveira \\ UCP, e-mail: juliiabaldez@gmail.com \\ TAVARES, Thaís \\ UCP, e-mail: thaistavares_mp@hotmail.com
}

\begin{abstract}
RESUMO
O objetivo deste estudo foi identificar os elementos arquitetônicos que contribuem para a permanência ou a transformação da experiência de multissensorialidade do Hotel Quitandinha, Petrópolis, RJ, entre sua inauguração e a atualidade. Houve análise comparativa de fotografias atuais e antigas. Foi aplicada, também, a técnica walkthrough. Verificou-se: a alteração das formas de apropriação e uso dos espaços, tendência à subutilização de parte da estrutura edificada, a redução da interatividade e ampliação da contemplação. Na primeira fase, percebem-se indícios da substituição dos valores de imersão e multissensorialidade pelo valor da observação visual.
\end{abstract}

Palavras-chave: Percepção ambiental, multissensorialidade, topofilia, Hotel Quitandinha.

\begin{abstract}
The aim of this study was to identify the architectural elements that contribute to the permanence or transformation in internal ambiences at Hotel Quitandinha, Petrópolis, RJ. The comparative analysis between old and new photographs was realized as come the walkthrough technique. It was verified: the alteration appropriation forms and uses of spaces, a tendency to underutilize part of the structure, the reduction of interaction aspects and the expansion of contemplation. In the first phase, is noticed the substitution of values of immersion and multisensoriality by the value of visual observation.
\end{abstract}

Keywords: Environmental perception, multisensoriality, topophilia, Hotel Quitandinha

\section{INTRODUÇÃO}

A reflexão trazida por este artigo é acerca da transformação das atmosferas do Palácio Quitandinha. O objetivo é identificar os elementos arquitetônicos que contribuem para a permanência ou a ruptura das ambiências internas no que tange aos estímulos multissensoriais, numa primeira fase, pelo estudo comparativo de fotografias antigas e atuais e visitas técnicas à edificação.

TALIN, L. C. A.; TRINDADE, A. B. C.; GUETTNAUER, D.; BALDEZ, J. S.; TAVARES, T. Hotel Quitandinha: Permanências e Rupturas na Experiência Multissensorial. In: SIMPÓSIO BRASILEIRO DE QUALIDADE DO PROJETO NO AMBIENTE CONSTRUÍDO, 6., 2019, Uberlândia. Anais... Uberlândia: PPGAU/FAUED/UFU, 2019. p. 126-136. DOI https://doi.org/10.14393/sbqp19013. 


\section{FUNDAMENTAÇÃO}

\subsection{Espaço, multissensorialidade e o registro fotográfico}

Existe um potencial das análises de fotografias históricas no avanço dos estudos espaciais, mesmo reconhecendo que a imagem expressa uma verdade relativa mostrada pelo enquadramento, ângulo e valores do fotógrafo (GOLTARA; MENDONÇA, 2015). Entler (2017) entende a fotografia como provocadora de questionamentos e sensações sobre características visíveis dos espaços representados, conformadoras da realidade no momento em que a fotografia foi feita. Assim podem-se estabelecer paralelos entre a paisagem atual e a passada pelos indicativos visuais de uso e apropriação do espaço pelas pessoas.

Os objetos, mobiliários, elementos e ornamentos arquitetônicos identificados em fotografias juntamente com análises de leiaute e formas de uso dos espaços apontam quais os estímulos estavam presentes no espaço do passado. Tuan (2012) indica que ambientes com estímulos sensoriais complexos são potenciais na promoção de sentimentos topofílicos. O autor define a topofilia como elo afetivo entre indivíduo e espaço.

Neves (2017) defende que a experiência em determinado ambiente depende da inserção na atmosfera, intangível, mas passível de percepção pelos estímulos sensoriais. Sensações como som, luz, cheiro umidade, temperatura se integram e criam um clima próprio do lugar que afeta o usuário, criando emoções e memórias. Assim, para a autora, os aspectos físicos e tangíveis da construção passam a ser elementos que compõem os sentidos humanos. É um argumento alinhado com a crítica de Pallasmaa (2011) à supremacia da visão em relação aos demais sentidos, com destaque para a função da arquitetura na reconciliação do indivíduo com o mundo a partir da compreensão do espaço como essencialmente multissensorial.

Tuan (2012) aponta que os sentimentos topofílicos do passado estão perdidos, podendo ser conhecidos apenas pela literatura, obras de arte e artefatos que permaneceram. As fotografias do passado comparadas às atuais podem evidenciar as relações de topofilia e multissensorialidade que são parte da essência da obra arquitetônica em análise. Nos relatos encontrados é evidenciada a intenção no projeto do Hotel Quitandinha em impactar e criar experiências aos visitantes. Para além do intuito de ser símbolo de luxo e beleza, que contém um conjunto de fatores políticos e socioeconômicos, o êxito do empreendimento dependia da conexão usuário-lugar.

\subsection{Hotel Cassino Quitandinha}

O Hotel Cassino (Figura 01) foi inaugurado em 12 de fevereiro de 1944. Conforme Garcia (2017), a década de 40 foi marcada pela prosperidade e pela presença freqüente da elite e figuras públicas nacionais e internacionais. Dois anos após a inauguração o cassino cessou atividades, contudo, o Hotel Quitandinha permaneceu como referência na realização de eventos de grande porte e convenções.

Atualmente conhecido como Palácio Quitandinha, foi projetado por equipe de arquitetos liderados por Luis Fossati, a parte interna do palácio Quitandinha foi decorada pela designer americana Dorothy Draper, que assinava cenários de filmes dos estúdios de Hollywood na década de 40. As intervenções no Palácio Quitandinha são alinhadas com a mistura de elementos clássicos com cores brilhantes e fortes e estamparias, observadas nas paredes, mármores e 
porcelanas. A designer buscou reproduzir a atmosfera tropical do Brasil, expressando-a nas formas orgânicas dos mobiliários e adornos, cores e luminárias (GARCIA, 2017).

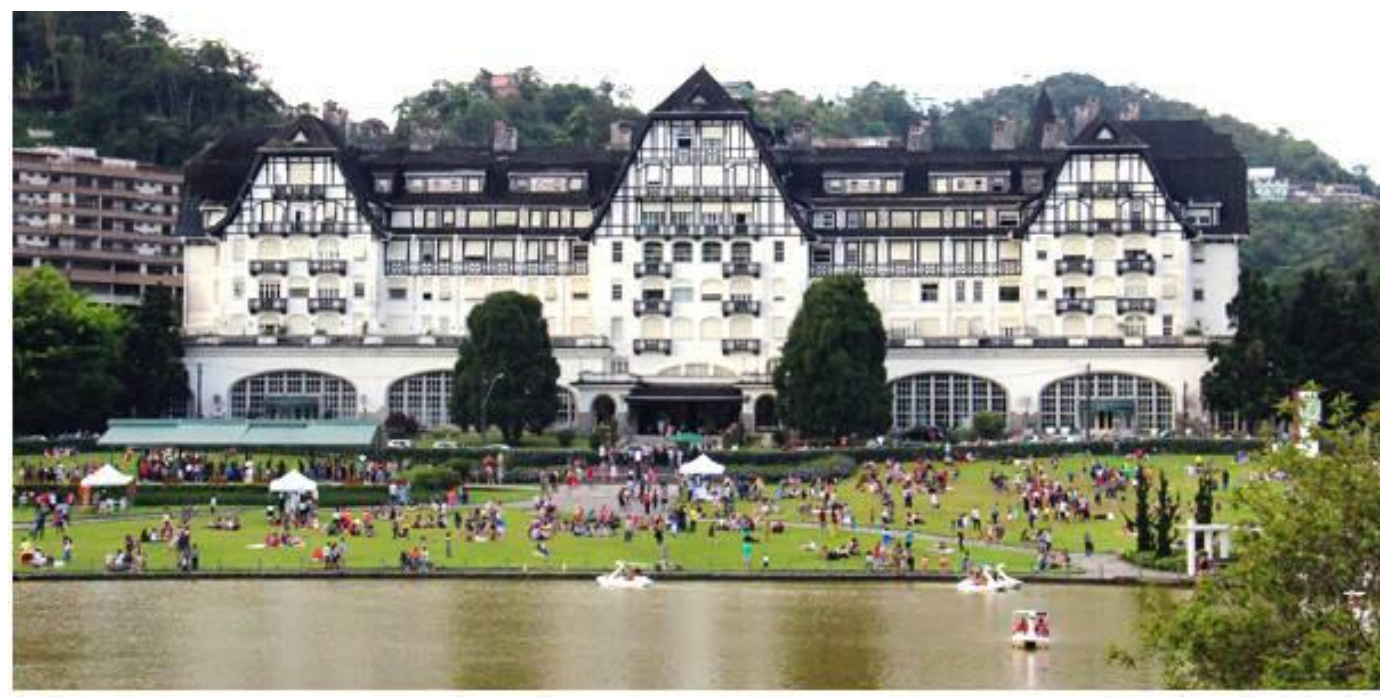

Figura 01 - Palácio Quitandinha

Fonte: Mariana Amaral, 2017.

Os tipos de usos originais como hotel com tratamentos termais com água radioativa, centro de convenções e eventos de grande porte não existem mais. Atualmente são realizados eventos musicais, teatrais e performáticos em algumas das salas, sendo o uso principal caracterizado como museu, com exposições itinerantes e para exposição da própria edificação, sendo permitido ao visitante circular por algumas salas específicas.

As formas de apropriação do espaço mudaram, fato que promove uma alteração de atmosferas e ambiências por si. Contudo, a proposta atual do espaço é a de inserção e vivência do projeto de luxo e beleza trazidos na concepção do Hotel. O quanto é possível experienciar essa realidade pela conformação arquitetônico-espacial atual?

\section{METODOLOGIA}

A pesquisa iniciou-se com o levantamento documental e bibliográfico. Foram selecionadas fotografias históricas e novo levantamento fotográfico, buscando a reprodução das fotos com ângulos similares. Aplicou-se a técnica da avaliação pós-ocupação de walkthrough, para recolher narrativas e informações sobre os ambientes. Haverá ainda verificação percepção ambiental junto aos usuários, não contempladas neste artigo, mas previstas como próxima fase da pesquisa.

Foram 10 (dez) ambientes fotografados e analisados. Foram confrontadas características de mobiliário, ornamentos, materiais de acabamento e elementos arquitetônicos, adicionadas pelas informações de usos atuais dos espaços obtidas pela visita acompanhada.

\section{RESULTADOS E DISCUSSÃO}

Sendo possível o entendimento de aspectos de percepção técnica e sensorial do ambiente construído por meio de análise comparativa de fotografias antigas e recentes, apresenta-se análise sobre as mudanças que ocorreram 
nos ambientes internos do palácio, seus usos, os mobiliários e as características arquitetônicas que possam transformar ambiências e atmosferas.

O Hotel Cassino Quitandinha apresentava usos internos diversificados com estruturas físicas particularizadas, mostrando a intenção da arquitetura em criar dinâmica nas ambiências internas. O acesso principal se dava pela Fachada frontal do imóvel, de frente para o lago, a partir do qual os fluxos eram distribuídos entre as atividades internas. Uma entrada secundária, lateral, era utilizada ocasionalmente.

O primeiro ambiente analisado é a Entrada do Salão de Diversões (Figura 02), próxima à entrada lateral da edificação. Antigamente, Garcia (2017) relata que apenas as pessoas cujas intenções eram acessar à àrea de teatro, jogos e diversões chegavam até essa sala, uma vez que o acesso lateral era secundário. As características arquitetônicas permanecem inalterados quanto ao identificado no registro fotográfico antigo. A sala possui materiais como o granito (ornamentos) e o gesso (nos ornamentos e candelabros), a presença de mobiliários orgânicos e com cores fortes, vitrines de comércio exclusivo e entradas marcantes para os salões adjacentes. Os motivos em gesso da entrada remetem à flora e à temática marítima, com ondas, conchas e animais marinhos. Esses elementos criam uma unidade com o conceito de tropicalidade, também aparente em ornamentos de outros ambientes internos na edificação. Os mobiliários orgânicos e centralizados conferiam fluidez a circulação das pessoas, organizando os fluxos das entradas aos distintos ambientes que se abrem ao Salão. O ambiente também poderia conformarse como uma área de concentração de pessoas e espera para as atividades, especialmente do cassino no Salão Mauá. Nas laterais, as vitrines de uma joalheria, impondo valores de consumo e luxo até mesmo nas áreas de circulação. Atualmente, em vez de jóias são expostas fotos do Hotel Cassino Quitandinha, indicando, sutilmente, a conversão para valorização da cultura e da história no lugar do consumo e do luxo. A sala que antes era de uso mais restrito tornou-se o acesso principal aos ambientes de exposição e eventos. São verificadas alterações de mobiliários, evidenciando-se a escala do mobiliário de antes que permitia a organização de fluxos enquanto que a atual apenas figura no eventual descanso de visitantes em espera. Hoje, na ocasião dos eventos, em sua maioria organizados pelo gestor do espaço SESCRIO, este salão também assume função de Foyer para concentração de público, espera para os espetáculos e comércio de alimentos. O local ainda funciona para distribuição e organização de pessoas, mas é responsável pelas primeiras impressões do usuário que chega para a visitação interna da edificação. A decisão em continuar o circuito de visitação ou partir para as atividades que acontecem no subsolo acontecem nesse ambiente. Não existem elementos fixos e específicos para estimular sentidos de percepção além da visão. Esses estímulos surgem pelo uso: ruídos de conversas que se sobrepõe, trechos de som vindos das salas próximas com músicos testando os equipamentos, cheiros de perfumes e comidas. O caráter atual traz novos significados ao espaço, ampliando sua importância e a quantidade de estímulos. Deixa de ser apenas um local de espera e de circulação para ser o convite ao circuito de visitação, o ambiente onde expectativas são criadas e onde os ânimos começam a se alinhar com o clima dos espetáculos. 

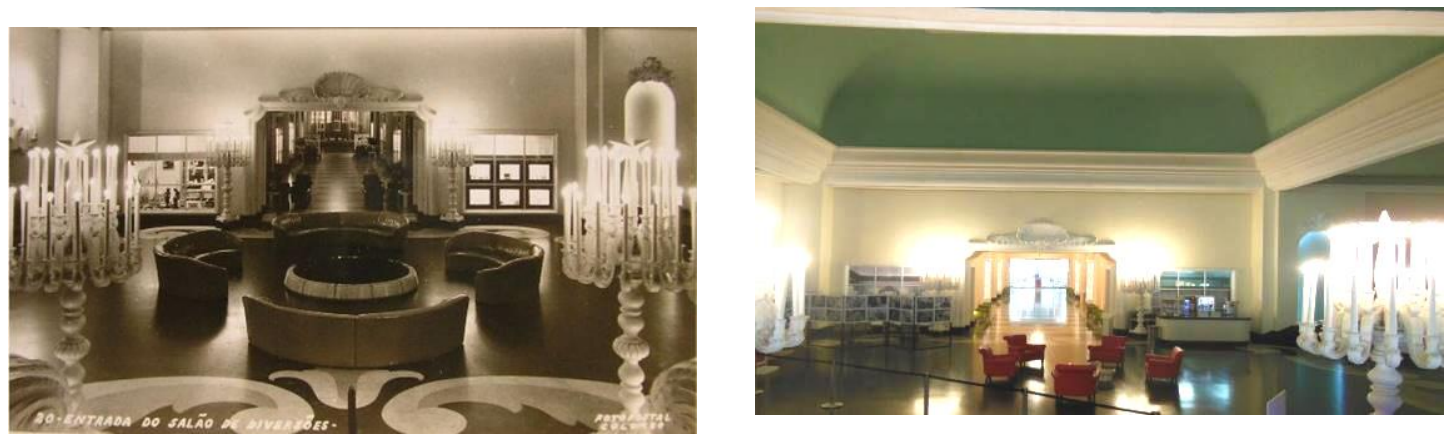

Figura 02 - Entrada do salão de diversões

Fonte: Fotopostal Colombo (à esquerda) e Júlia Baldez (à direita)

A Entrada do Salão de Diversões distribui os fluxos para três espaços: a galeria das Estrelas e o Salão Mavá, descritos mais adiante neste artigo, e o Teatro Mecanizado. O Teatro Mecanizado (Figura 03) tem capacidade para até 1.000 espectadores e abrigava eventos ligados ao teatro, música, literatura e artes, com destaque para os luxuosos bailes de carnaval. Com três palcos giratórios, o show continuava permanentemente, pois enquanto um palco se fechava ao mesmo tempo outro se abria. Este é um espaço de grandes proporções e de uso intenso, tanto no passado quanto no presente, sendo um dos espaços mais utilizados pelo SESC-RIO para eventos. É um ambiente que deverá ser aprofundado, mas cujos registros fotográficos antigos não permitem observações acerca de estímulos multissensoriais espaciais e, portanto, será estudado futuramente por outros métodos.
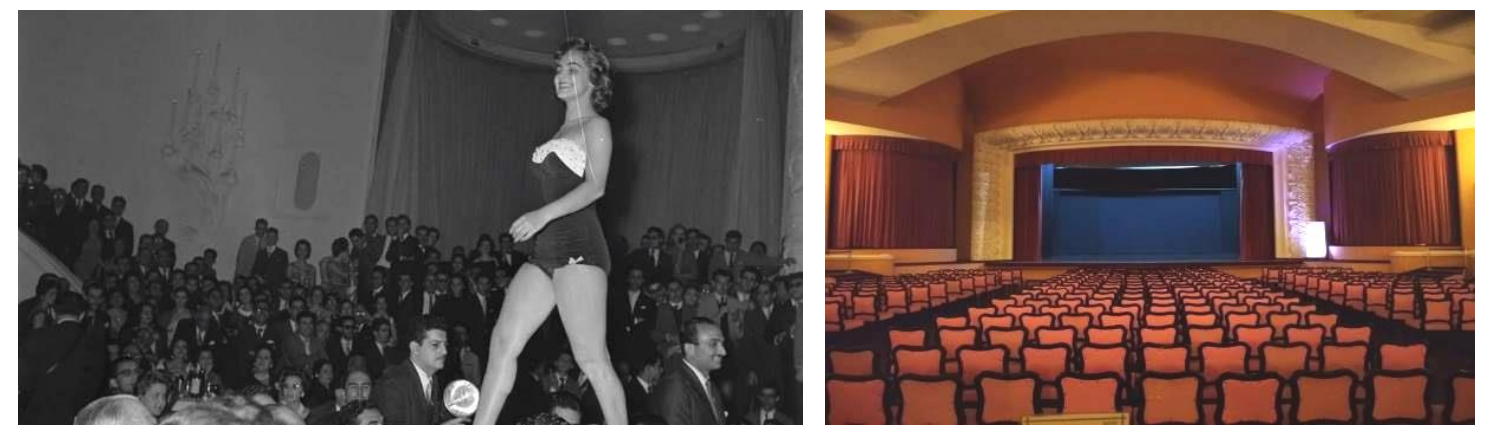

Figura 03 - Teatro Mecanizado

Fonte: Arquivo O Globo (à esquerda) e Thaís Tavares (à direita)

Com 21 metros de altura e 51 metros de circunferência a cúpula do Palácio Quitandinha é uma das principais atrações de visitantes, foi considerada um marco na história do concreto armado na América do Sul (GARCIA, 2007). O Salão Mauá (Figura 04) era o ambiente principal do antigo cassino, onde ficavam as mesas e máquinas dos jogos de aposta.

As janelas cobertas com cortinas de veludo inibiam a luz natural e isolavam o usuário do ambiente externo, impedindo-o de perceber o passar das horas. $O$ teto da cúpula, com chapiscos azuis, era originalmente adornado por estrelas metálicas, como verificado nos relatos e no walkthrough. O volume monumental da sala com superfícies reflexivas e o formato côncavo da cúpula conformam um ambiente sonoro muito reverberante, favorecendo o eco e focalizações de som, concentrando a energia sonora em lugares específicos. Desse modo, mesmo que o cassino estivesse com poucas pessoas, a audição indicava um ambiente muito frequentado. Essa conformação espacial objetivava iludir o usuário e deixá-lo estimulado, para sustentar sua permanência no local. Atualmente, todo o mobiliário foi removido. O Salão é 
usado para exposições e instalações de arte, uso contemplativo. A acústica ainda fornece estímulos aos usuários, mesmo não sendo funcional, desperta a curiosidade e incita a experimentação do espaço.
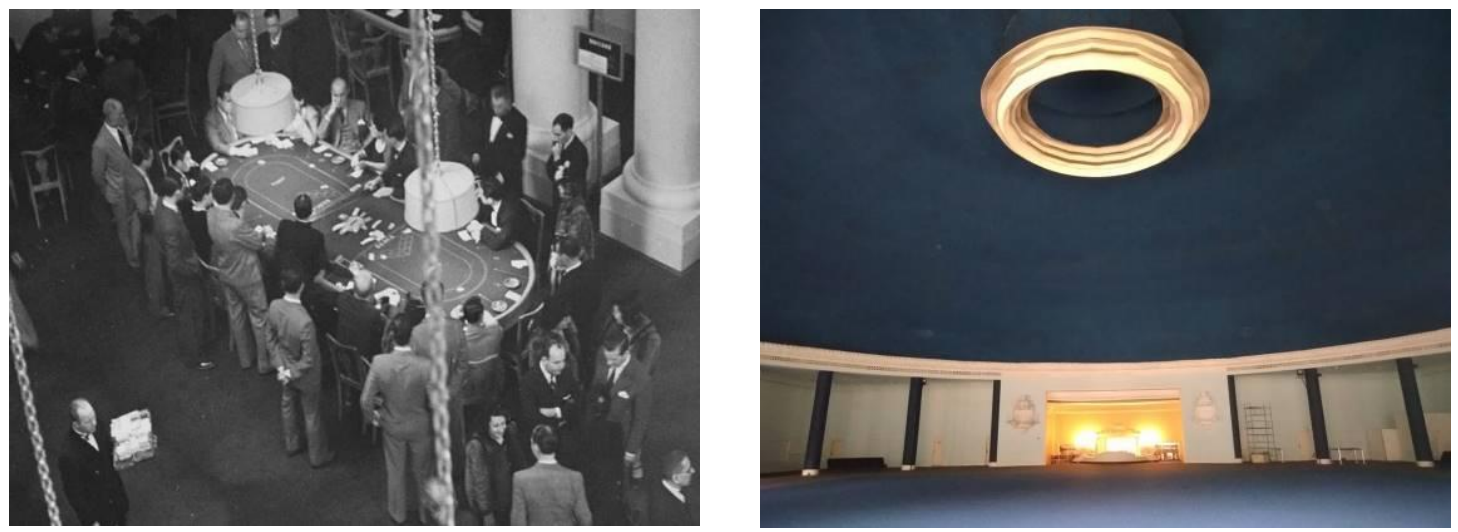

Figura 04 - Salão Mauá

Fonte: Acervo Palácio Quitandinha (à esquerda) e Thaís Tavares (à direita)

Quando o visitante opta por conhecer a estrutura interna do Palácio Quitandinha ele passa da Entrada do Salão de Diversões para a Galeria das Estrelas (Figura 05). Atualmente, este ambiente é de conexão, com bancos tipo recamier dispostos junto às paredes e fotos de celebridades que frequentaram o Hotel Cassino. Poucas alterações são observadas no espaço, revestimentos e luminárias continuam os mesmos, o pórtico de passagem com uma grande concha reforçando transições e criando conexões com outros ornamentos, as luminárias de cristal pendentes em formato de estrela estabelecendo ritmos na visada. As cores claras e os detalhes em branco para amplitude deste ambiente que se apresentava como de passagem, mas que indica outro uso quando se observa o mobiliário existente na foto antiga. São observados quatro núcleos de poltronas baixas e largas, com mesas de apoio laterais e luminárias de piso tipo abajures. As poltronas dispostas de frente umas para as outras e o microambiente criado pelo mobiliário sugerem que a galeria era um local de permanência, propício para conversas intimistas de grupos pequenos. Com pé direito mais baixo que dos espaços próximos e as luminárias pendentes aproximando-se dos usuários, este também era local de preparação para entrada no Café Concerto.
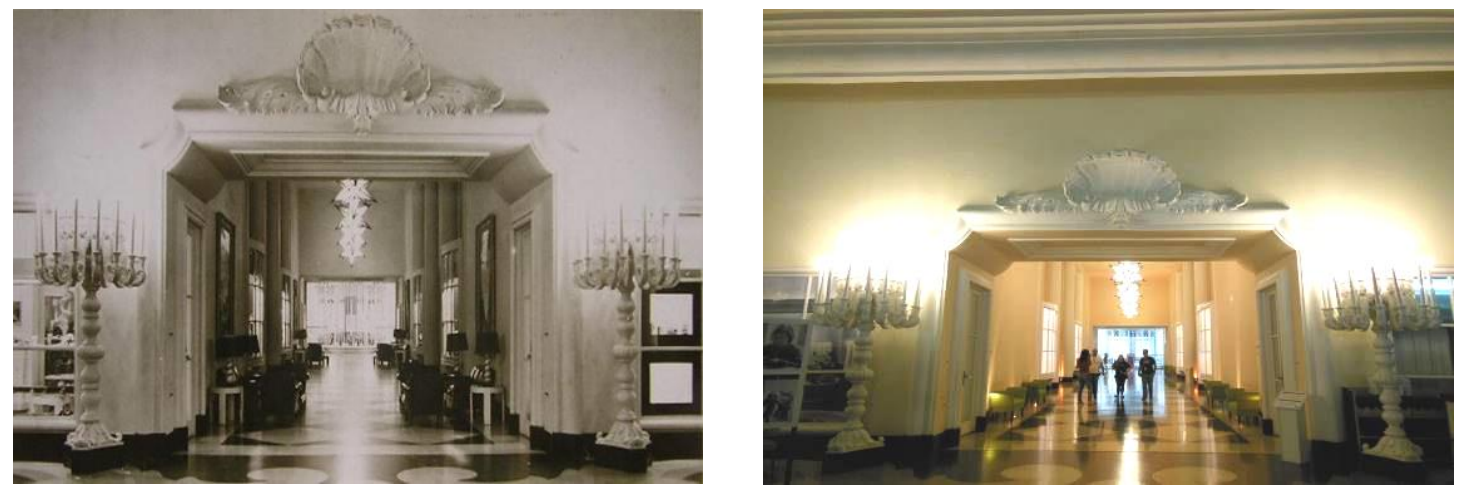

Figura 05 - Corredor e Galeria das Estrelas

Fonte: Fotopostal Colombo (à esquerda) e Júlia Baldez (à direita)

O Café Concerto (Figura 06) possui decoração inspirada na flora nacional, sendo as paredes decoradas com imagens de folhas de bananeiras, fumo, café e orquídeas, a entrada marcada por um espelho bisotê veneziano, procedente da ilha de Murano (GARCIA, 2007). Destaca-se o detalhe funcional do bar que permitia ao espectador, mesmo de costas para o palco, 
ser capaz de acompanhar as apresentações através de um jogo de espelhos ornados em Taquarucú. A disposição das mesas e cadeiras oferecia, em qualquer ângulo, uma visão completa do palco. O teto baixo e modulado com iluminação indireta também auxiliava na acústica intimista e envolvente. Este é um ambiente cujos estímulos auditivos são protagonistas, especialmente pelas atividades musicais que aconteciam no palco. O espaço passou por revitalização, a decoração foi restaurada. Assim, os elementos construídos e de mobiliário são dotados de caráter de permanência entre o vislumbrado por usuários da atualidade e do passado. Atualmente, recebe eventos promovidos pelo SESC-RIO tendo uso mais esporádico, uma vez que o mobiliário existente dificulta a flexibilização de leiaute e possui pequena capacidade de público, o que inviabiliza financeiramente algumas apresentações artísticas. Não possui mais a atividade de bar, o que também reduz um dos estímulos sensoriais: o olfativo.
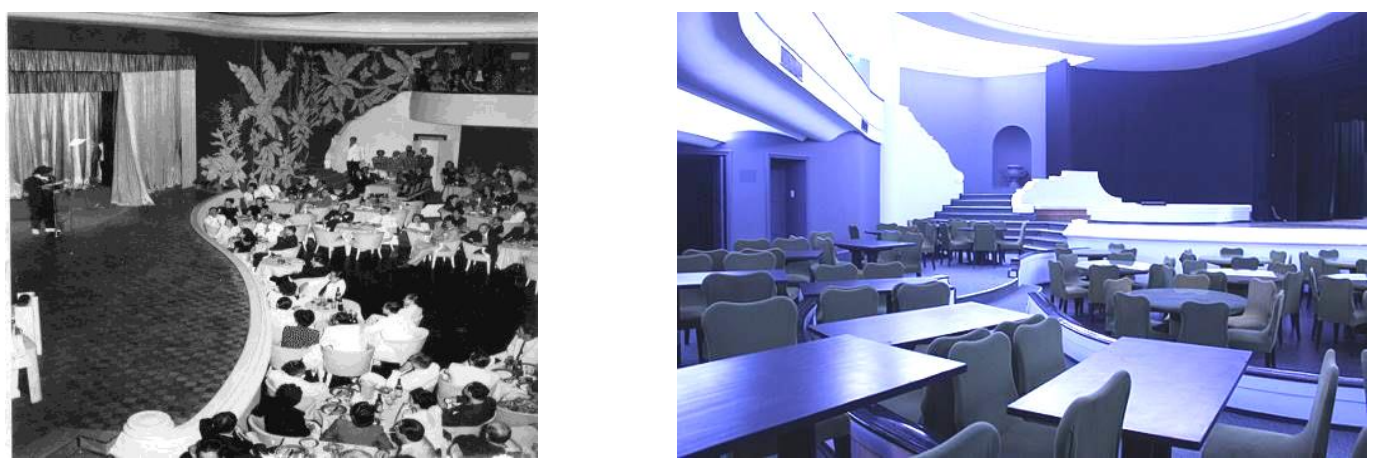

Figura 06 - Café Concerto

Fonte: Orlando Kloh (à esquerda) e Mariana Amaral (à direita)

A piscina (Figura 07), localizada na área de transição entre área de diversões e de relações pessoais e diplomática se destaca pela concepção, forma e volume. Sendo idealizada a partir da forma de um piano de calda, com pinturas feitas pelo artista Santa Rosa, inspiradas na obra "20.000 Léguas Submarinas" de Júlio Verne. A representação das pinturas tem caráter mais informal e menos requintada em relação aos demais ambientes do Hotel Cassino. O uso da cor verde substitui a cor rosa característica, e está associada a folhagens, frescor, águas claras, bem-estar e demais fatores, como apresenta Freitas(2007).

O espaço abrigava acesso à sauna, piscina com profundidade de $4 \mathrm{~m}$, onde eram realizados saltos e dança aquática, e um bar às margens da piscina, que possuía vista para a rua pelas janelas adjacentes. Por estar no nível da rua e com janelas para a fachada lateral, observam-se cortinas que possivelmente objetivavam aumentar a privacidade. Um dos aspectos espaciais marcantes é a proporção entre tamanho e profundidade da piscina e o volume do espaço em si.

Atualmente, todos os mobiliários do local foram removidos, mas as condições arquitetônicas e espaciais permanecem. A área não pode ser acessada pelo visitante, que não pode entrar no espaço e remontar atmosferas do passado por meio de sentidos distintos, ou da conjuntura espacial. Apenas o aspecto visual é oportunizado. Em seu uso original, este talvez fosse um dos espaços com mais estímulos sensoriais: água e vapor na pele, cheiro de eucalipto e de alimentos e bebidas do bar, luz difusa, sons de conversas animadas e de água, movimentada pelo nado e pelos mergulhos. 

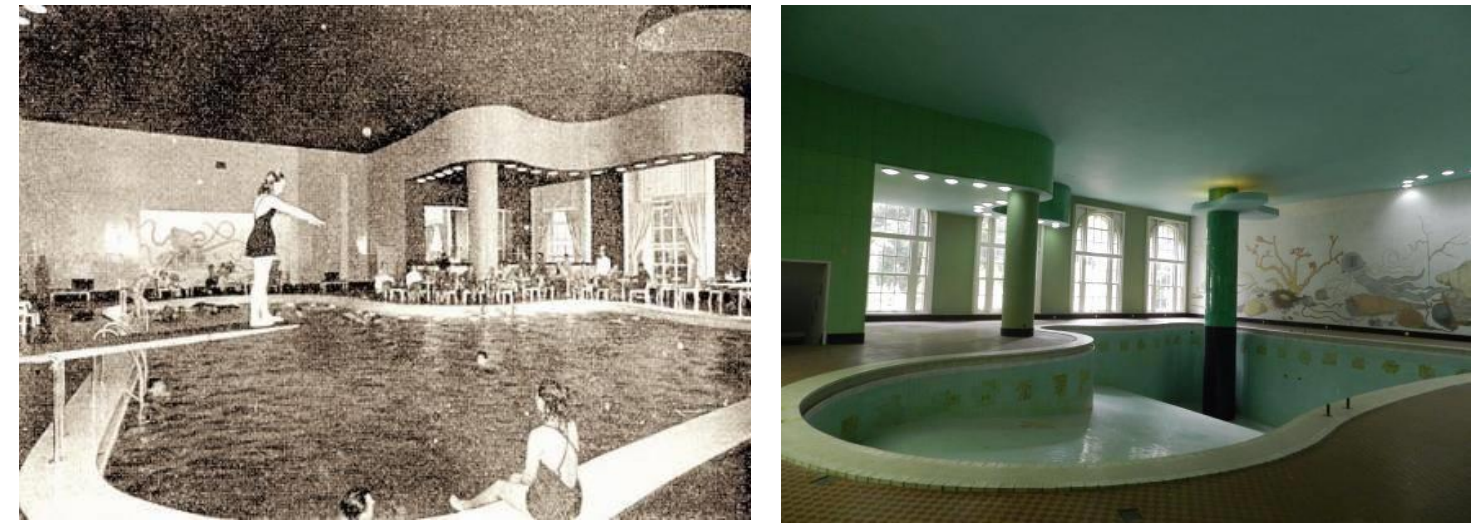

Figura 07 - Piscina Térmica do hotel

Fonte: Fotopostal Colombo (à esquerda) e Júlia Baldez (à direita)

A Sala de Correspondência (Figura 08), usada para comunicação pessoal e de negócios, são notadas alterações de cor e a retirada do carpete que cobria o piso. Há a colocação de delimitação física do espaço permitido ao visitante atualmente. A imersão nas fotos permite identificar a transformação de valores espaciais de aconchego e privacidade em valores de restrição e impessoalidade. Apesar de ser espaço para visitação e permanência, a oportunidade de observar a sala do mesmo ponto de vista, sentado, não é possível ao visitante que hoje frequenta o espaço.
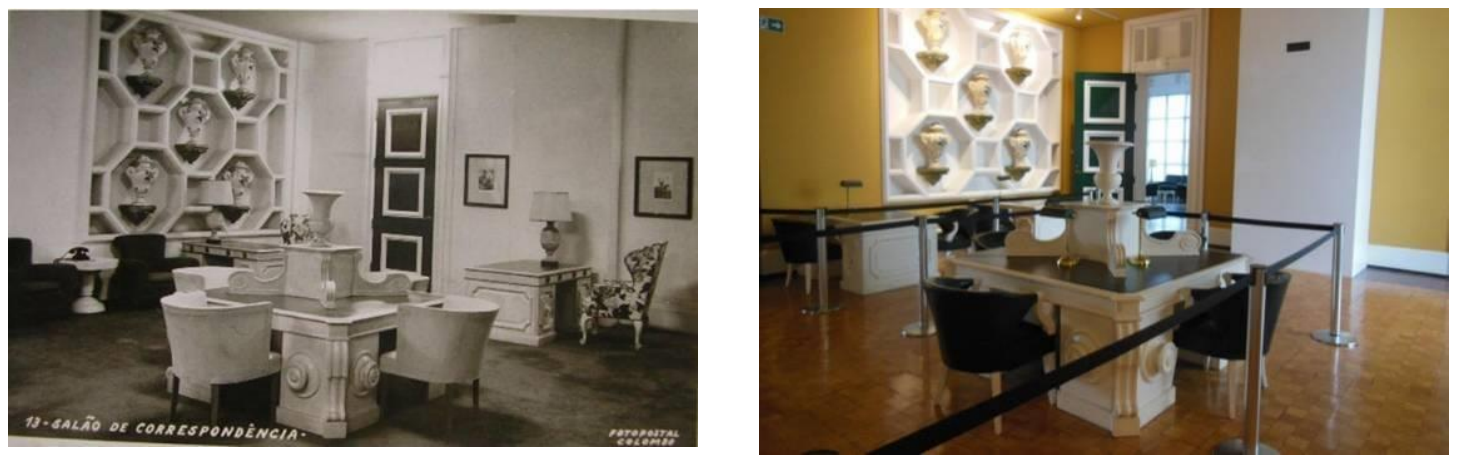

Figura 08- Sala de Correspondência

Fonte: Fotopostal Colombo(à esquerda) e Júlia Baldez (à direita)

No Jardim de Inverno (Figura 09) as cores claras, os mobiliários de estrutura esbelta e a fonte central, remetiam a intenção principal de Doroty que o local transmitisse leveza e frescor e seguindo valores estéticos da gaiola onde se criavam pássaros. A geometria rígida do piso e das portas contrastava com mobiliários e ornamentos. Existe uma unidade na identidade visual deste ambiente com outros do interior da edificação, com especial destaque às formas orgânicas com motivos marinhos.

Identifica-se a conversão de espaço de permanência e convívio em circulação, que apenas distribui os fluxos entre as salas adjacentes. Os mobiliários de estofado estampado e estrutura orgânica que marcavam o espaço como área de encontro e convívio, próxima ao restaurante e com estímulos sonoros e olfativos como a fonte e a gaiola de pássaros. Atualmente, estes estímulos não existem, e o mobiliário escasso não convida à permanência. O aspecto escultórico da fonte foi valorizado com a redução de estímulos visuais que competiam pela atenção do usuário. 

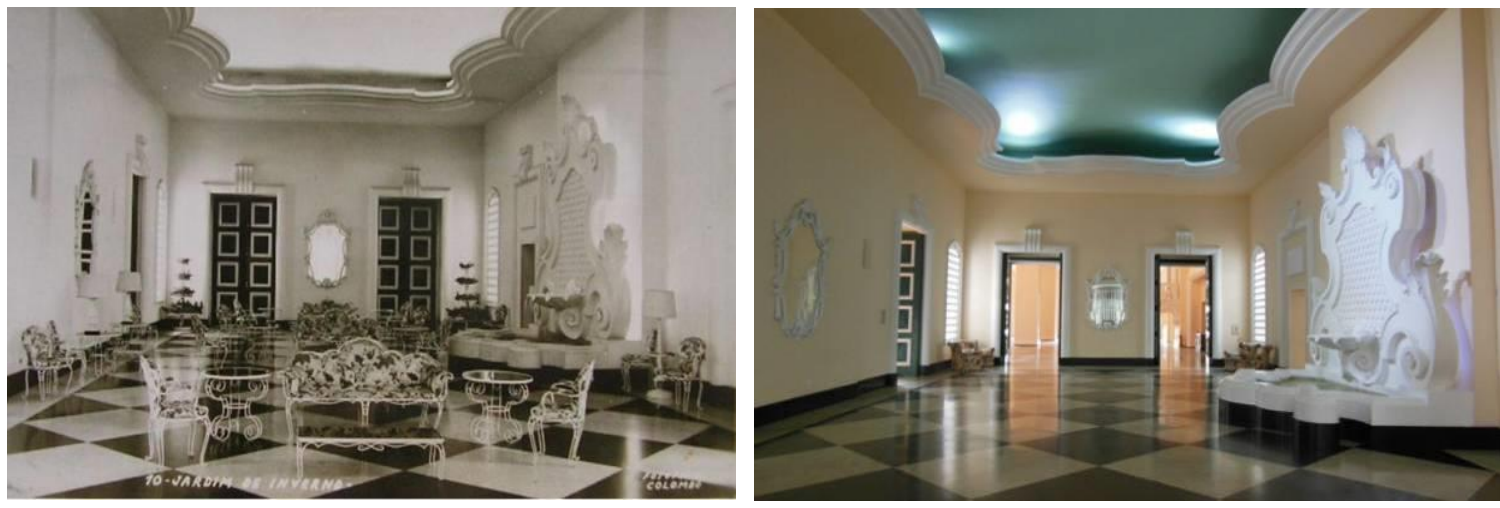

Figura 09 - Jardim de Inverno

Fonte: Fotopostal Colombo (à esquerda) e Júlia Baldez (à direita)

O restaurante central (Figura 10) era o principal local de refeições do Hotel Cassino. Um dos espaços cujas alterações de mobiliários mais marcadamente descaracterizaram a ambiência do espaço. A sala de refeições tinha atmosfera de aproximação entre pessoas e aconchego dada pela presença de tapetes e cortinas. Os elementos de revestimento de parede, adornos e luminárias foram mantidos, mas, atualmente, não mais existem carpetes e cortinas e todas as mesas e cadeiras foram removidas. O local não segue a função inicial, servindo apenas para contemplação da arquitetura. O mezanino (com balaustrada visível na parte superior esquerda das fotos na Figura 08) que antigamente era o palco para as bandas convidadas, encontra-se inutilizado. Mesmo sendo permitido ao visitante entrar no espaço não é possível a compreensão da atmosfera antiga do restaurante, não são fornecidas informações suficientes para entender as dinâmicas de uso deste espaço, especialmente quanto aos estímulos sensoriais auditivos, olfativos e táteis.
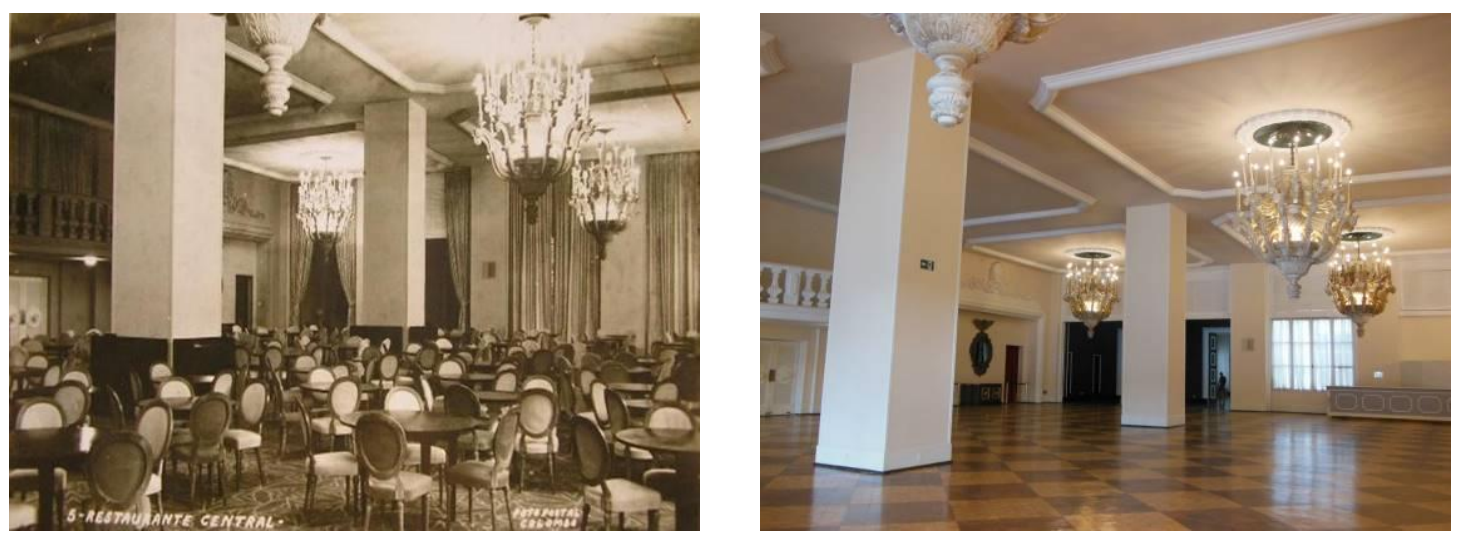

Figura 10 - Restaurante Central

Fonte: Fotopostal Colombo (à esquerda) e Júlia Baldez (à direita)

A varanda de inverno (Figura 11), era usada para entretenimento das crianças junto às babás, provavelmente enquanto os pais usufruíam das refeições do restaurante, pois são ambientes adjacentes. Na varanda, há vista para a área externa com piscina em formato de cavalo marinho e jardim privado. Também constavam na varanda de inverno mesas de ping-pong e jogos para jovens. Arquitetonicamente, pouco se observa de mudança: os revestimentos e as luminárias continuam os mesmos, bem como ornamentos e esquadrias para luz natural. O aspecto de impessoalidade e passagem são os mais marcantes hodiernamente. $O$ visitante, que ao visitar esta área já circulou pelos diversos espaços como Salão Mauá, Teatro Mecanizado, Café Concerto, Jardim de Inverno, Sala de Correspondência entre outros, já teve tempo de se habituar à 
estética da edificação e tem poucos estímulos para permanência. Este ambiente caracteriza-se mais pela contemplação dos jardins externos que pela sua configuração interna.
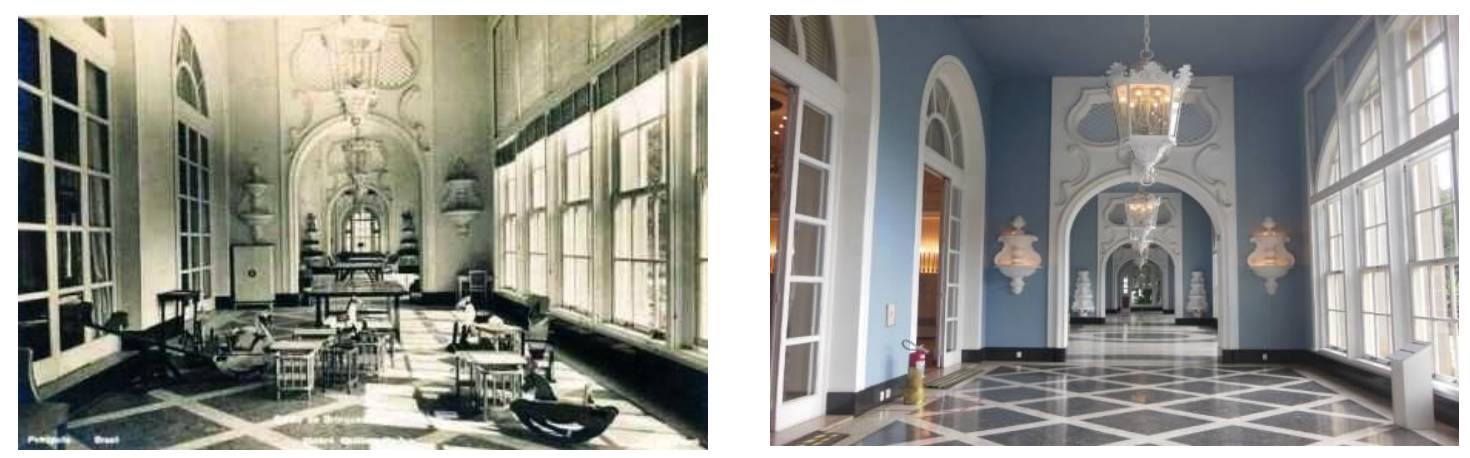

Figura 11 - Varanda de Inverno

Fonte: Fotopostal Colombo (à esquerda) e Júlia Baldez (à direita)

O Bar Central (Figura 12) também encontra-se preservado. O acesso é feito pela varanda e é próximo do hall de entrada do hotel, que se configurava anteriormente como acesso principal. O tom imponente do verde escuro, sendo enquadrado pelos adornos e detalhes brancos e salmão claro, cria contraste e destaca o aparador fixo. O mobiliário foi completamente substituído. As mesas e cadeiras estofadas de bar foram trocadas por cadeiras de escritório, contemporâneas, organizadas em fileiras que atendem às conferências e palestras que acontecem atualmente neste espaço. O carpete que reduzia ruídos e conferia aconchego foi retirado. $O$ ambiente de relaxamento foi convertido em corporativo. O aspecto sonoro, antes coadjuvante dado pelas conversas descontraídas, é agora de relevância funcional: se a acústica não funcionar, a inteligibilidade do discurso é prejudicada. Contudo, não são observados ajustes espaciais para este fim. Estímulos olfativos e táteis provenientes da atividade se perderam.
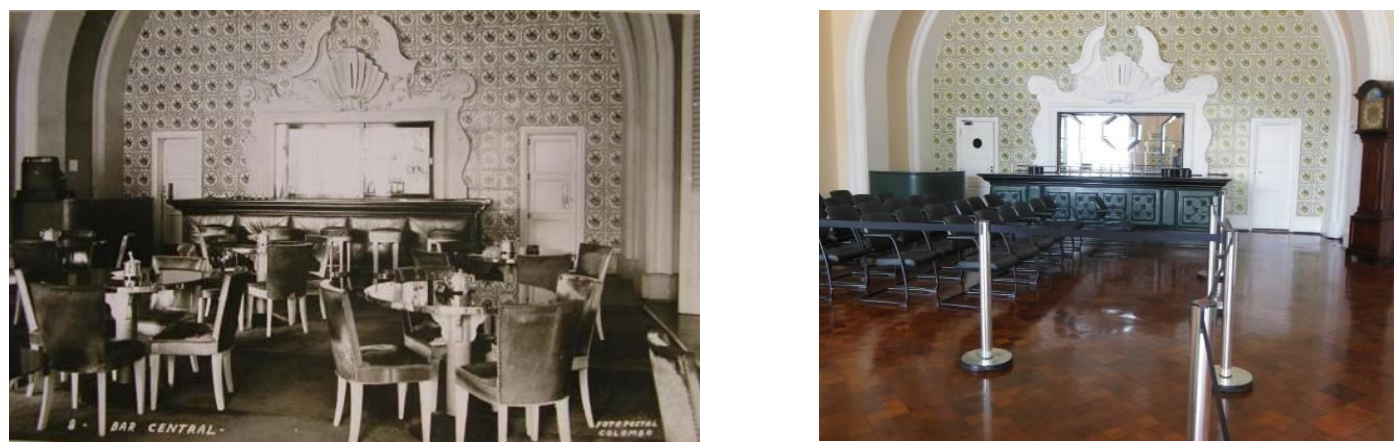

Figura 12 - Bar Central

Fonte: Fotopostal Colombo (à esquerda) e Júlia Baldez (à direita)

Dentre os dez ambientes analisados, dois são os ambientes em que não houve alteração na mobília, à qual se atribui parte da ambientação e conformação de atmosferas. Nos demais espaços, a supressão de mobiliário e a conversão de usos de permanência em circulações suprime também elementos que estimulam sentidos de percepção além da visão, como audição, tato e olfato.

\section{CONSIDERAÇÕES FINAIS}

A primeira fase da pesquisa mostrou que a alteração de elementos concretos como mobiliários, cortinas e a água provoca rupturas, interferindo na experiência, apesar permanência das características arquitetônicas fundamentais associadas aos elementos construtivos e ornamentos. A 
conversão de antigos espaços de permanência em espaços de passagem aponta para a redução dos estímulos, de sensações e emoções que poderiam ser provocadas pela exposição mais prolongada do indivíduo, como a distribuição da luz natural e dos sons de água da fonte. Com a alteração dos aspectos de interação indíviduo-ambiente e para contemplação, o potencial de impacto na percepção do espaço se mostra reduzido ao sentido da visão na maior parte dos ambientes.

É importante considerar o estímulo sonoro no Salão Mauá que, mesmo tendo sido esvaziado de todo mobiliário, ainda se mostra estimulante pela experiência auditiva do eco, além da visualização do espaço.

Entretanto, cabe ainda o aprofundamento para identificar novas atmosferas, ambiências e percepções dos usuários. A experiência dos indivíduos pode conduzir a diretrizes que aprimorem a imersão na realidade do Hotel Quitandinha em sua fase de uso mais intensivo na década de 40.

\section{REFERÊNCIAS}

ENTLER, Ronaldo. A fotografia e as representações do tempo. Revista Galáxia, São Paulo, n. 14, p. 29-46, dez. 2007.

FREITAS, Ana Karina Miranda de. Psicodinâmica das cores em comunicação. NUCOM, ano 4, n. 12, Limeira, 2007.

GOLTARA, Giovani Bonadiman; MENDONÇA, Eneida Maria Souza. O emprego da fotografia como método de análise da transformação da paisagem o caso de Anchieta. Paisagem e Ambiente: Ensaios, n. 36, São Paulo, p. 119 - 136, 2015.

NEVES, Juliana Duarte. Arquitetura Sensorial: a arte de projetar para todos os sentidos. 1. Ed. Rio de Janeiro: Mauad, 2017.

PALLASMAA, Juhani. Os olhos da pele: a arquitetura e os sentidos. Tradução: Alexandre Salvaterra. Porto Alegre: Bookman, 2011.

GARCIA, Luiz Boralli. A história do Quitandinha: da construção aos dias atuais. Petrópolis:Editora Bem Cultural, 2017.

TUAN, Yi-Fu. Topofilia: um estudo da percepção, atitudes e valores do meio ambiente. Tradução: Lívia de Oliveira. Londrina: Eduel, 2012. 